\title{
"Reference waters" in French laboratories involved in tritium monitoring: how tritium-free are they?
}

\author{
E. Fourré ${ }^{1}$, P. Jean-Baptiste ${ }^{1}$, A. Dapoigny ${ }^{1}$, E. Ansoborlo ${ }^{2}$ and N. Baglan ${ }^{3}$ \\ 1 Laboratoire des Sciences du Climat et de l'Environnement, UMR 8212 CEA-CNRS-UVSQ/IPSL, CEN Saclay, 91191 Gif-sur-Yvette, France. \\ 2 CETAMA, CEA/DEN/DCRP, Marcoule, 30207 Bagnols-sur-Cèze, France. \\ 3 CEA/DAM/DIF, 91297 Arpajon, France.
}

Received 16 December 2013 - Accepted 23 January 2014

\begin{abstract}
This paper presents a comprehensive survey of the tritium content of "reference waters" in real working conditions by French laboratories involved in environmental monitoring. Reference waters are virtually tritium-free waters used to determine blanks for the analytical system and to check for any contamination. It is therefore crucial to be sure of the low tritium content of these waters as this can limit the sensitivity and accuracy of the measurements. Water from the commercial brand "Abatilles" is widely used in French laboratories and nine samples were analyzed in this study. Three samples from other deep aquifers were also included. The results all range from $0.004 \pm 0.004 \mathrm{~Bq} / \mathrm{kg}$ to $0.175 \pm 0.011 \mathrm{~Bq} / \mathrm{kg}$, well below the $0.5 \mathrm{~Bq} / \mathrm{kg}$ advised by the French Safety Authority. The spread of the results can mainly be attributed to contamination through plastic during bottle storage. As expected, two samples from demineralized tap water showed higher tritium activities $(0.3-0.35 \mathrm{~Bq} / \mathrm{kg})$. Both waters are suitable as reference water for routine monitoring (DL of about $10 \mathrm{~Bq} / \mathrm{kg}$ ) but should be used with caution for activities in the $\mathrm{Bq} / \mathrm{kg}$ range.
\end{abstract}

Keywords: tritium / environmental monitoring / low doses / groundwaters / mass spectrometry

\section{Introduction}

Tritium is produced naturally through various interactions of cosmic rays and atoms in the atmosphere, but is also a by-product of some nuclear and research reactor operations. Therefore, there is an increasing interest in following tritium behavior and measuring its distribution in the environment.

Tritium can exist in several forms, such as gaseous (HT, HTO, organic molecules), liquid (HTO or organic molecules in solution) or OBT, which can become incorporated into living organisms (vegetables, animals, humans). Given these complexities, tritium monitoring in the environment and throughout the food chain requires the development of recognized or standardized methods within a regulatory framework, even though there are currently no associated Certified Reference Materials (CRM).

There are many different methods for analyzing the various forms of tritium in environmental samples (ASN, 2010; Baglan et al., 2010). Most laboratories involved in routine tritium monitoring for radiation protection are equipped with liquid scintillation counting systems, and furnace combustion for solid organic matter.

In order to meet constantly more demanding analytical requirements in terms of sensitivity and accuracy for low activity measurements, it is crucial for these laboratories that a reliable

\footnotetext{
a elise.fourre@lsce.ipsl.fr
}

reference water be available. By reference water, we mean virtually tritium-free water that is used to determine blanks for the analytical system and to check for any contamination. Groundwaters with no surface water contamination which are old enough for natural tritium to have decayed to negligible levels (half life of $4497 \pm 9$ days $^{1}$ ) were selected to meet this objective.

In France, the CETAMA (Comité d'établissement des méthodes d'analyse) plays an important role in the field of analytical sciences and provides support to national analytical laboratories. In 2011 it was decided to launch a national-scale evaluation of the reference waters used in participating laboratories. Fourteen samples sent by twelve laboratories were therefore analyzed using the ${ }^{3} \mathrm{He}$ ingrowth method (Clarke et al., 1976) at the LSCE.

\section{Samples}

Water from the Abatilles commercial brand is widely used among French laboratories as a reference water. This mineral water is pumped from a depth of $472 \mathrm{~m}$ in the upper and middle calcareous Eocene aquifer near Arcachon, in the maritime pine Landes Forest (Gironde, France). It is particularly well-known for being nitrate-free.

\footnotetext{
${ }^{1}$ www.nucleide.org/DDEP_WG/Nuclides/H-3_com.pdf.
} 
Table 1. Reference water samples and tritium activities.

\begin{tabular}{lcccc}
\hline Sample & Conditioned in & Bottling date & ${ }^{3} \mathbf{H}(\mathbf{B q} / \mathbf{k g})$ & $\mathbf{1 \sigma}(\mathbf{B q} / \mathbf{k g})$ \\
\hline Abatilles-1 & glass vial & Unknown & 0.004 & 0.004 \\
Abatilles-2 & commercial bottle & July 2011 & 0.018 & 0.005 \\
Abatilles-3 & commercial bottle & March 2011 & 0.021 & 0.006 \\
Abatilles-4 & commercial bottle & August 2010 & 0.027 & 0.005 \\
Abatilles-5 & commercial bottle & September 2010 & 0.047 & 0.005 \\
Abatilles-6 & commercial bottle & April 2010 & 0.059 & 0.005 \\
Abatilles-7 & plastic vial & December 2008 & 0.110 & 0.006 \\
Abatilles-8 & plastic vial & July 2011 & 0.165 & 0.008 \\
Abatilles-9 & commercial bottle & May 2011 & 0.175 & 0.011 \\
Deep borehole-1 & glass vial & & 0.005 & 0.004 \\
Deep borehole-2 & glass vial & & 0.045 & 0.005 \\
Deep borehole-3 & plastic vial & & 0.163 & 0.009 \\
Demineralized water-1 & glass vial & & 0.299 & 0.012 \\
Demineralized water-2 & glass vial & & 0.354 & 0.011 \\
\hline
\end{tabular}

For this study, nine laboratories provided samples of this Abatilles water. Six of them sent the commercial plastic sealed bottles directly, so the bottling date was available. The other three labs transferred the Abatilles water to a different flask prior to its shipment. The bottling date was known for two of them.

Two laboratories use demineralized water. Here, tap water passes through AQUADEM ${ }^{\circledR}$ (Veolia) columns packed with resin to remove dissolved substances by ion exchange.

Lastly, three laboratories have regular access to deep waters and use them as reference waters: (i) a 750-m-deep borehole into the Neocomian aquifer at Bruyères le Châtel (Essonne, Paris Basin); (ii) Chaudfontaine, a thermal spring in the Belgian Ardennes, from water seeping down to $1600 \mathrm{~m}$ depth through limestone and schist layers; (iii) Vignoles water, from a confined aquifer in tertiary limestone (Côte d'Or, Burgundy). These waters were provided directly after sampling, with storage in the lab from 0 to a maximum of a couple of days.

$$
\text { All samples are listed in Table } 1 .
$$

\section{Experimental procedure}

The ${ }^{3} \mathrm{He}$ ingrowth technique (Clarke et al., 1976) is based on the measurement of the tritium radioactive decay product $\left({ }^{3} \mathrm{He}\right)$ by mass spectrometry. Over the last three decades, it has been used extensively in oceanography and hydrology for the measurement of low to very low levels of tritium, down to a few $\mathrm{mBq} / \mathrm{L}$. The principle involves removing ${ }^{3} \mathrm{He}$ initially dissolved in the sample by degassing under vacuum, then storing it in a helium-tight container to allow the accumulation of tritiugenic ${ }^{3} \mathrm{He}\left({ }^{3} \mathrm{He}_{\text {tri }}\right)$. The tritium content at the container closure time is then directly computed from the mass spectrometric determination of ${ }^{3} \mathrm{He}$ produced during the time of storage $\tau$ : ${ }^{3} \mathrm{H}($ in $\mathrm{mol})={ }^{3} \mathrm{He}_{\text {tri }}($ in $\mathrm{mol}) \times \frac{1}{1-e^{-\lambda \tau}}$, where $\lambda$ is the tritium decay constant.

In practice, waters received from the laboratories involved in this study were stored and further transferred into glass bulbs (about $50 \mathrm{~g}$ of water) inside a glove box flushed with dry air to avoid any contamination from air-borne moisture. 100-mL Corning 1724 glass bulbs were used, specially selected for the very low He diffusivity of this type of glass. In order to minimize ${ }^{3} \mathrm{He}$ blanks, the bulbs were pre-baked for 24 hours at $600{ }^{\circ} \mathrm{C}$ under argon flow to remove helium dissolved in the glass itself. The bulbs were then attached to a high-vacuum line, placed in an ultrasonic bath and pumped out for about 20 minutes down to $<10^{-6}$ Torr, before closure by flame-sealing. Given the very low tritium levels expected in this study, the samples were stored for at least 15 months at $-20{ }^{\circ} \mathrm{C}$ to further minimize helium diffusion through the glass.

After the storage period, the bulbs were connected to the inlet system of a MAP215-50 mass spectrometer operating in static mode and specially designed for low-level ${ }^{3} \mathrm{He}$ measurement, including an electrostatic filter lowering the ${ }^{3} \mathrm{He}$ background $(<0.05$ count $/ \mathrm{sec}) .{ }^{4} \mathrm{He}$ was measured as well: the signal, usually very low $\left(<4 \times 10^{-14} \mathrm{~mol}\right)$, corresponds to the overall blank of the method (residue after the degassing step, line + mass spectrometer background). It was converted into a non-tritiugenic ${ }^{3} \mathrm{He}$ signal by applying the ${ }^{3} \mathrm{He} /{ }^{4} \mathrm{He}$ ratio of the blank. ${ }^{3} \mathrm{He}$ and ${ }^{4} \mathrm{He}$ measurements were calibrated against an air standard $\left(\mathrm{He}=5.24 \mathrm{ppm},{ }^{3} \mathrm{He} /{ }^{4} \mathrm{He}=1.38 \times 10^{-6}\right)$. A more detailed description of the procedure and mass spectrometer characterization is given in Jean-Baptiste et al. $(1992,2010)$.

\section{Results and discussion}

The results of the tritium activity measurements are shown in Figure 1 and details given in Table 1. The values range from $0.004 \pm 0.004 \mathrm{~Bq} / \mathrm{kg}$ to $0.354 \pm 0.011 \mathrm{~Bq} / \mathrm{kg}$ (at one sigma uncertainty).

For regulatory environmental monitoring, this activity is strongly advised to be lower than $0.5 \mathrm{~Bq} / \mathrm{L}$ according to the International Standard ISO 9698. Therefore, all the waters analyzed in this study, which show activities significantly below $0.5 \mathrm{~Bq} / \mathrm{L}$, comply with this recommendation. 


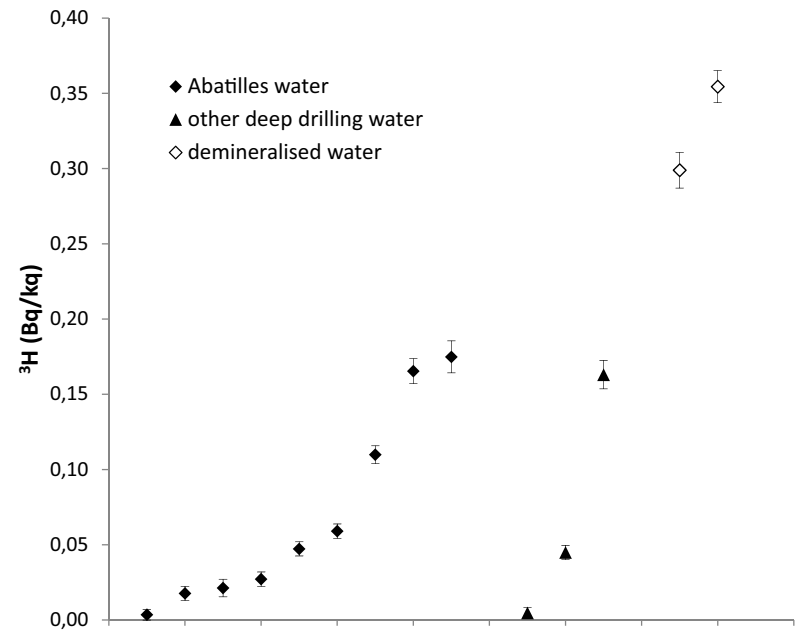

Fig. 1. Tritium activities measured in the different reference waters. Error bars are one sigma.

The two highest values found correspond to demineralized water. Tritium was present initially in the tap water used and may further exchange with the lab air moisture and/or dead volume in the resin column during the demineralization process.

Abatilles water tritium activities in this study ranged from $0.004 \pm 0.004 \mathrm{~Bq} / \mathrm{kg}$ to $0.175 \pm 0.011 \mathrm{~Bq} / \mathrm{kg}$. There is no clear correlation with the bottling date. The range of observed values can be attributed to contamination by atmospheric moisture through the commercially sealed plastic bottles from bottling time and during storage in the laboratories. The value of $0.175 \mathrm{~Bq} / \mathrm{kg}$ was in fact measured on an Abatilles bottle from a laboratory located close to a well-known source of ${ }^{3} \mathrm{H}$ emission. To clearly demonstrate the contamination through sealed plastic bottles, the tritium activity of a sealed bottle of Abatilles water stored since 2006 on the shelf of the LSCE in Saclay was measured. It rose to $1.92 \pm 0.04 \mathrm{~Bq} / \mathrm{kg}$, which cannot be considered surprising given that the Saclay facility itself releases small amounts of tritium, thus locally increasing the tritium content in water vapor and rain above the regional background.

In a previous Abatilles water measurement campaign in 1999-2000, the tritium activities were spread over a narrower range, with a maximum at $0.031 \pm 0.015 \mathrm{~Bq} / \mathrm{kg}$. However, in this case the bottles were sent directly to the LSCE by the CETAMA, without a transit time in the different participating laboratories. It was therefore less representative of the analytical labs' conditions.

The three samples pumped from deep boreholes other than Abatilles mineral water show the same range of activities, from $0.005 \pm 0.004 \mathrm{~Bq} / \mathrm{kg}$ to $0.163 \pm 0.009 \mathrm{~Bq} / \mathrm{kg}$, and are therefore as suitable as Abatilles water for use as reference water.

\section{Conclusion}

One interesting point of this study of the reference waters used by French laboratories involved in tritium environmental monitoring is that it reflects laboratory working conditions. All the water samples come from the laboratories' shelves and have not been specially supplied for this purpose. Therefore, if the range of activities is wider than previously reported, in particular for Abatilles water, it is more representative of actual laboratory conditions.

The main conclusion is that as far as the detection limit advised in the ISO 9698 standard is concerned, all the waters comply with the requirements (activity significantly below $0.5 \mathrm{~Bq} / \mathrm{kg}$ ) and can be confidently used by laboratories. In fact, the maximum activity measured was about $0.17 \mathrm{~Bq} / \mathrm{kg}$ for reference water from a deep aquifer, and $0.35 \mathrm{~Bq} / \mathrm{kg}$ for demineralized water.

A few recommendations can be made based on the conclusions of this study.

Firstly, reference water should be renewed frequently, in order to avoid long-term storage. There is no advisable maximum storage time since it depends on (i) the tritium activity in the vicinity of the storage room, and (ii) the detection limit targeted. Therefore, each lab has to determine its own optimal frequency of supply.

Secondly, in order to obtain demineralized water, processing tap water through a resin column should be considered with special caution, as this may lead to tritium activities significantly higher than those found in mineral water from deep aquifers. An alternative possibility would be to use Abatilles water (or other deep borehole water) and set up a distillation unit inside a glove box flushed with dry air (or other gas), so that the whole process would take place without any air moisture contact.

Acknowledgements. We thank all the participating laboratories: C. Tanguy (LASEM Brest), H. Djaffar, L. Gravier, S. Lemius and Y. Lossé (CEA), R. Le Meignen (EDF), M. Mahu and L. Tenailleau (GEA), J. Loyen and C. Cossonnet (IRSN), M. Lhermitte (LASEM Cherbourg), and I. Deniau (SUBATECH).

\section{References}

ASN (2010) Livre Blanc du Tritium, Autorité de Sûreté Nucléaire, available from http://www. asn. fr.

Baglan N., Ansoborlo E., Cossonnet C., Fouhal L., Deniau I., Mokili M., Henry A., Fourré E., Olivier A. (2010) Métrologie du tritium dans différentes matrices: cas du tritium organiquement lié, Radioprotection 45 (3), 369-390.

Clarke W.B., Jenkins W.J., Top Z. (1976) Determination of tritium by mass-spectrometric measurement of He-3, Appl. Radiat. Isotopes 27, 515-522.

Jean-Baptiste P., Mantisi F., Dapoigny A., Stievenard M. (1992) Design and performance of a mass spectrometric facility for measuring helium isotopes in natural waters and for low-level tritium determination by the ${ }^{3} \mathrm{He}$ ingrowth method, Appl. Radiat. Isotopes 43, 881-891.

Jean-Baptiste P., Fourré E., Dapoigny A., Baumier D., Baglan N., Alanic G. (2010) ${ }^{3} \mathrm{He}$ mass spectrometry for very low-level measurement of organic tritium in environmental samples, J. Environ. Rad. 101, 185-190. 